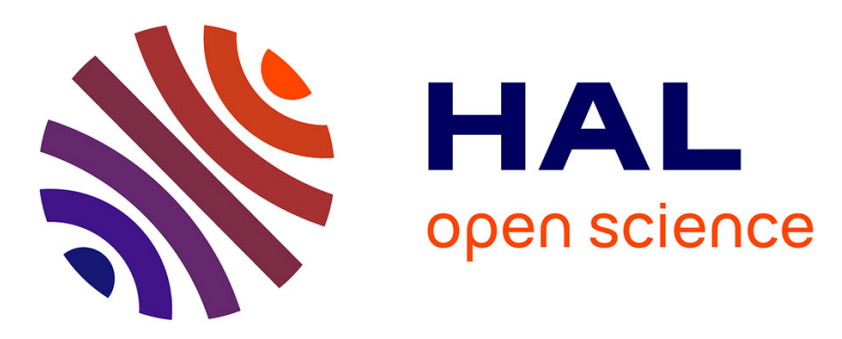

\title{
Investigating phrasing levels in French: Is there a difference between nuclear and prenuclear accents?
}

Mariapaola d'Imperio, Roxane Bertrand, Albert Di Cristo, Cristel Portes

\section{To cite this version:}

Mariapaola d'Imperio, Roxane Bertrand, Albert Di Cristo, Cristel Portes. Investigating phrasing levels in French: Is there a difference between nuclear and prenuclear accents?. J. Camacho, V. Deprez, N. Flores, L. Sanchez. Selected Papers from the 36th Linguistic Symposium on Romance Languages (LSRL), John Benjamins Publishing Company, pp.97-110, 2007. hal-00265188

\section{HAL Id: hal-00265188 \\ https://hal.science/hal-00265188}

Submitted on 18 Mar 2008

HAL is a multi-disciplinary open access archive for the deposit and dissemination of scientific research documents, whether they are published or not. The documents may come from teaching and research institutions in France or abroad, or from public or private research centers.
L'archive ouverte pluridisciplinaire HAL, est destinée au dépôt et à la diffusion de documents scientifiques de niveau recherche, publiés ou non, émanant des établissements d'enseignement et de recherche français ou étrangers, des laboratoires publics ou privés. 


\title{
INVESTIGATING PHRASING LEVELS IN FRENCH: IS THERE A DIFFERENCE BETWEEN NUCLEAR AND PRENUCLEAR ACCENTS?
}

\author{
M. D'IMPERIO, R. BERTRAND, A. DI CRISTO AND C. PORTES \\ Aix-Marseille 1, CNRS, Aix-en-Provence, France
}

\section{Introduction}

Despite the very large body of literature on prosody in French (for a review, see Di Cristo 1998, in press; Lacheret-Dujour and Beaugendre 1999), there is still no consensus about some fundamental issues such as whether positing the existence of word-level or merely phrasal stress (Dell 1984), which and how many constituents should be included in the prosodic hierarchy as well as the number and shape of contrastive pitch accents. Recent models of French intonation posit the existence of two prosodic constituents above the word. A lower level constituent has been described in earlier literature with various terminological definitions, i.e., Phonological Word (Selkirk 1972), Prosodic Word (Vaissière 1974), Rhythmic Word (Pasdeloup 1990), Rhythmic Unit (Di Cristo and Hirst 1993). Despite the terminological differences, it is uncontroversially accepted that this is the domain of primary stress (accent primaire) which would define its right edge, while an optional secondary stress (accent secondaire), or initial accent (Fónagy 1980, Pasdeloup 1990) would mark its left edge. Recently, units of the same level have been proposed which are either defined in purely tonal terms, as the Accentual Phrase (AP, Jun and Fougeron 1995, 2000, 2002), or as rhythmic constituents built on the basis of prosodic phonological rules (thus making explicit reference to the syntax), as the Phonological Phrase (PP) of Post (2000). ${ }^{1}$

Above the AP/PP level (and being also the highest level), we find the Intonation Phrase (IP). This constituent is generally defined in, admittedly, a rather fuzzy way as a unit showing, among the other things, "melodic cohesion". From a functional point of view, it has also been proposed that discourse segmentation in IPs is mainly justified by semantic and pragmatic constraints (Selkirk 1984).

\footnotetext{
${ }^{1}$ The two basic units are found also in traditional work on French intonation (Di Cristo 1976) under the names of Groupe Accentuel (for the AP) and Groupe Intonatif (for the IP).
} 
In this paper we will treat only primary accentuation, while the role and the characteristics of the initial accent will be ignored. This is also because recent phonological and phonetic analyses of this accent (Jun and Fougeron 1995, 2000, Welby 2006, Welby and Loevenbruck, in press) suggest that it cannot be treated as a pitch accent proper, since it lacks the metrical strength and the phonetic correlates of an actual pitch accent (such as marked lengthening of the syllable rhyme, stable anchoring of the peak, etc.; see Welby 2006 for a detailed discussion). ${ }^{2}$ Hence, we will only concentrate on primary accentuation at two possible hierarchical levels, i.e., at the end of a non-final AP and at the end of an IP-final AP.

According to the British tradition (Cruttenden 1997), the level of phrasing defined by the IP is also the domain of the "nuclear accent", which is positionally defined as being the last accent within this constituent, as well as being the most prominent one in the prosodic hierarchy. Any preceding accent in the intonation phrase is defined as "prenuclear".

Within the autosegmental-metrical model of intonation, only the positional definition remains, though defining a lower phrasing level, that of the intermediate phrase (Beckman and Pierrehumbert 1986). Specifically, the nuclear accent is the accent immediately preceding the phrase accent, which is the tone determining the melodic level after the end of the stressed/nuclear syllable up to the end of the phrase. However, no special status is given to the nuclear accent in this framework, since the nuclear "contour" of the British tradition will be simply the result of a nuclear pitch accent (taken from an inventory of pitch accents which is common between prenuclear and nuclear position) plus at least an edge tone (phrase accent by itself, or a phrase accent plus a boundary tone).

In the models of French intonation proposed by Jun and Fougeron (2002) and Post (2000) there is no formal distinction between nuclear and prenuclear accent type (see Figure 1). Specifically, the pitch accent associated with the "primary stress" position has been described as either a $\mathrm{H}^{*}$ (Post 2000) or as a LH* (Jun \& Fougeron 2002) pitch accent (see Figure 1), independent of the position within the IP. ${ }^{3}$

\footnotetext{
${ }^{2}$ Though our paper does not deal directly with this issue, it appears that there are strong phonological and phonetic arguments in support of the idea that the non-emphatic initial accent of French can be treated as an edge-seeking tonal event (initial rise, see also D'Imperio et al. in press for some articulatory correlates of this event).

${ }^{3}$ Note however that Post's model allows for a mechanism of L-insertion rendering the nuclear rise a $\mathrm{LH}^{*}$ accent. Here we only take the underlying description of the pitch accent type as relevant for discussing the proposals.
} 


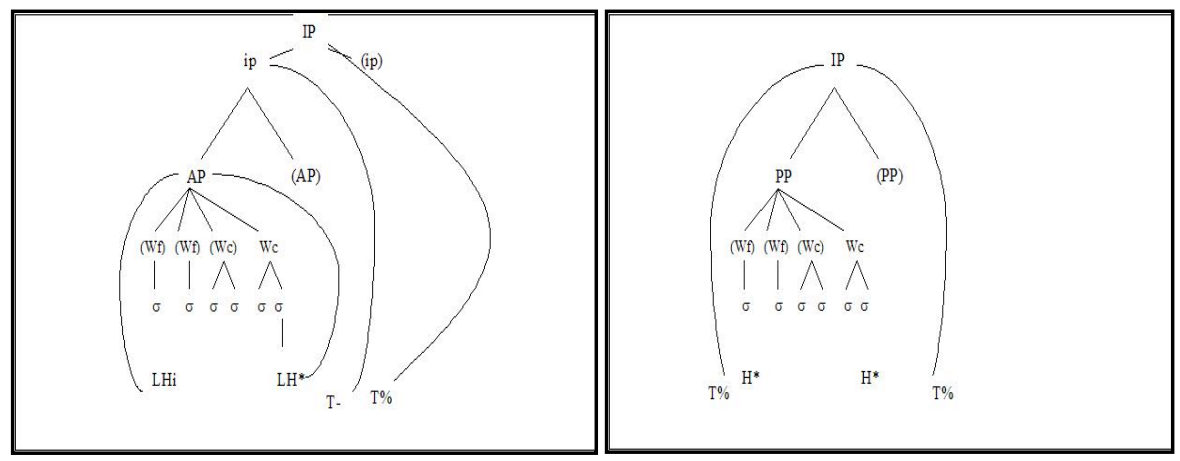

Figure 1: Schematic representation of the hierarchical models proposed by (left panel) Jun and Fougeron (2002) and (right panel) Post (2000).

An alternative view (Di Cristo 1999) claims that a phonological distinction between these two accents should be kept for French, which makes the basis of the hypothesis tested here. Specifically, Di Cristo proposes that the distinctive mark of the intonation phrase is the presence of a nuclear accent, which represents the Designated Terminal Element of this unit. The nuclear accent is invested with the highest level of prominence in the stress system of the language, can signal focus, and would contribute in a decisive way to the interpretation of intonation phrase (continuation, finality, assertion, question, etc). It is thus expected, according to this view, that the nuclear accent would carry some prosodic properties different from those which accompany the realization of the final accent of the AP, i.e., of the final prenuclear accent. However, until now, these differences were not established in a convincing way, hence the need to conduct our investigation.

A related issue is that of variability due to regional varieties of French under consideration. The bulk of the research on French intonation has concentrated on Standard French, though recent work is beginning to investigate formal differences among regional varieties (Post et al. 2006). Hence, we decided to include this variable in our study by analysing speakers of two different regional accents (Standard vs. South-Eastern French). We will show that, despite the regional differences, a global pattern emerges from the investigation of our data. The formal dimensions that we will explore are, specifically, tonal alignment and scaling. By alignment one generally means the temporal location of tonal targets within the segmental string (see Prieto et al. 1995, Arvaniti and Ladd 1995, Ladd et al. 2000), while by scaling one means the melodic (fundamental frequency, or F0) value of the target.

Recently, work on the alignment of tonal targets in the intonation system of various languages (Arvaniti et al. 2000, D'Imperio 2000) has been 
employed in order to explore tune-text association. Also, arguments based on alignment differences have been employed in order to motivate contrastive phonological analyses of pitch accents (D’Imperio 2002, Prieto et al. 2005).

Earlier work (Silverman and Pierrehumbert 1990) has offered possible phonetic and phonological explanations for the alignment differences found between the prenuclear and the nuclear $\mathrm{H}^{*}$ accent of American English (where the prenuclear peak is later than the nuclear one) by invoking, for instance, the repulsing effect on accent peak timing of an immediately following phrase accent in the nuclear case. In our study we will consider the possible effect of the presence of a $\mathrm{H} \%$ boundary tone in the case of the final/nuclear accents, and its consequences for the timing and scaling of both $\mathrm{L}$ and $\mathrm{H}$ targets within the rise. Namely, if the analysis by Post is borne out, we predict that the scaling of the nuclear/final $\mathrm{H}$ target would be higher, given the upstepping function of the H\% boundary tone. However, though Post's model does not make any predictions about tonal alignment, we could predict that the $\mathrm{LH}$ rise would be anticipated (in line with the tonal repulsion hypothesis of Silverman and Pierrehumbert 1990) because of the presence of a subsequent $\mathrm{H} \%$ boundary tone.

Hence, this work aims at investigating the potential difference between an IP-final rising contour and an IP-internal (for instance, accentual-phrase final) rising contour, which are usually described as containing the same rising pitch accent. The issue of constituency is intimately linked to the issue explored in this paper, i.e., whether IP-final rising accents should be kept distinct from non-final rising accents within the inventory of French pitch accent types. This would amount to saying that nuclear (in the sense of IPfinal) and prenuclear accents (non-final) would be contrastive. The nature and the implications of this contrast will be discussed below.

\section{Corpus and Methodology}

\subsection{Corpus}

Utterances produced by two speakers, one for Standard and the other for South-Eastern French, were analyzed. The subjects read 7 repetitions of 8 different target sentences (namely 56 experimental sentences) embedded in short dialogues. Each experimental sentence contained only one target word including one target syllable, /mi/. The variables manipulated (see Table 1) were syllable structure (open vs. closed), absolute position of the target word within the IP (final vs. non-final) and number of potential APs (2 or 3). An example of an open syllable, non-final target, embedded within a 2-AP utterance, is given in (1). 

(1) $\left\{[\text { les amis }]_{\mathrm{AP}}\right.$
[de mami $\left.]_{\mathrm{AP}}\right\}_{\mathrm{IP}}$, ils n'arrivent que demain.
"The friends
of grandma,
they will only come tomorrow"

All the experimental sentences were left-dislocated utterances in order to induce a nuclear rising IP-final contour (Di Cristo 1998) clearly contrasting with the prenuclear AP final rise (see Figures 1 and 2). The hypothesis tested was that both tonal movements can be described as $\mathrm{H}^{*}$, as in the model proposed by Post (2000), and specifically that neither auditory nor acoustic differences will be found between them.

\begin{tabular}{|c|c|c|}
\hline \multirow{2}{*}{ SYLL } & \multicolumn{2}{|r|}{ AP-Num } \\
\hline & 2 APs & 3 APs \\
\hline Open/Fin. & {$[[\text { La famille] [des amis }]]_{I P}$} & [[La famille] [du beau-frère] [des amis] $]_{I P}$ \\
\hline Closed/Fin. & {$[[\text { Les amis] [de Camille }]]_{I P}$} & {$\left[[\text { Les amis] [du beau-frère] [de Camille }]_{I P}\right.$} \\
\hline Open/Init. & {$\left[[\right.$ Les amis $][\text { de mami }]_{I P}$} & {$\left[[\text { Les amis] [du beau-frère] [de mami] }]_{I P}\right.$} \\
\hline Closed/Init.1 & {$\left[[\text { La Camille }]\left[d^{\prime} \text { Amelie }\right]\right]_{I P}$} & {$\left[[\text { La Camille }][\text { du beau-frère }]\left[d^{\prime} \text { Amelie }\right]\right]_{I P}$} \\
\hline
\end{tabular}

Table 1: The different types of left dislocated sentences embedded within the test utterances. Syllable structure (open vs. closed) and position within the IP (final vs. non-final) are shown in the first column, while in the second we show number of APs (2 or 3) within the IP.

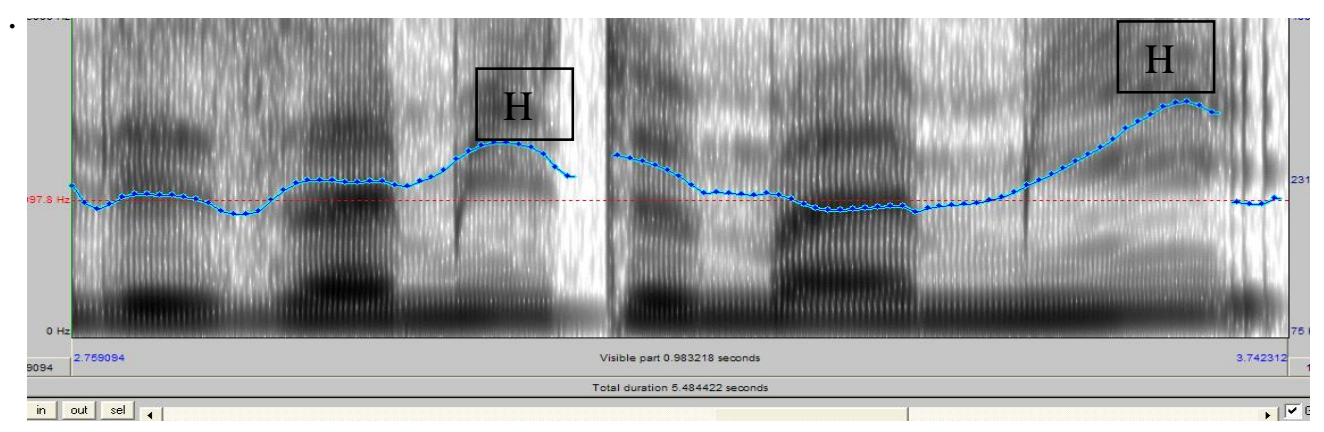

Figure 2: Spectrograph, waveform and FO curve of the 2-AP utterance "les amis de mamie" of sentence (1) above. H targets for the two rising pitch accents are also shown.

\subsection{Transcription and Measurements}

As for the acoustic measures, alignment and scaling were considered as indices of tonal structure. We also believed that in order to get the most complete view of the phenomenon at hand we needed to follow a double approach. That is we performed both an auditory and an acoustic analysis of the tonal movement. 
2.2.1 Auditory transcription. The auditory transcription was designed in order to verify the number and level (AP or IP) of prosodic phrases within the utterance as well as the type of tonal movement associated with the final stressed syllable of each phrase.

The left dislocated sentences were annotated by 2 experts who had to mark the presence vs absence of a prosodic break after each word. ${ }^{4}$ Next, annotators had to identify the kind of tonal movement corresponding to each AP final position. Since current models of French intonation do not precisely establish a contrast between these two accent types, a hybrid (non standard) notation of tonal movements, more dynamic and holistic, was adopted: "R" for a perceived rise vs. "S/H" for a level accent (same, high level, relative to preceding syllable), and L for a perceived low or falling accent.

2.2.2 Transcription results. Annotators were in a total agreement concerning the number, the location and the break levels. As expected, they noted 2 or 3 breaks corresponding to the presence of 2 or 3 APs within the left-dislocated sentence, a weak break at the right edge of a non-final IP and a strong break at the right edge of the IP.

The only notable differences concern the type of tonal movement perceived by the experts, specifically on the prenuclear accent ${ }^{5}$ (the AP-final accent in non IP-final position). While there was a consensus in identifying the nuclear accent as $\mathrm{R}$, there were some differences for the prenuclear accent transcription, which was transcribed either as a $\mathrm{R}$ or as a $\mathrm{S} / \mathrm{H}$ (and very rarely as a L). For the South-Eastern French speaker both annotators were in agreement for 40 responses (over 56) with 38 common $\mathrm{R}$ responses and 2 common $\mathrm{S} / \mathrm{H}$ responses.

On the other hand, for the standard French speaker the scores for both annotators agree for 44 responses (over 56), though this time with 43 common $\mathrm{S} / \mathrm{H}$ and only 1 common $\mathrm{R}$ response.

To sum up, we found a consensus for the transcription of the final/nuclear accent, which was always perceived by both transcribers as a rising movement for both speakers. On the other hand, the prenuclear accent was transcribed either as a rising or a high level accent, with a contrasting behaviour according to the speaker.

\footnotetext{
${ }^{4}$ The break levels were "0" (no break), "1" (weak break), "2" (strong break) and "?" for an ambiguous or indeterminate break.

${ }^{5}$ Note that the prenuclear accents transcribed were always final within the AP, and not instances of initial accent (cf. §1).
} 
2.2.3 Acoustic measurements. The measures performed were as follows:

- stressed syllable duration

- F0 height for both the initial minimum (L target) and the final maximum $(\mathrm{H}$ target) of the pitch movement associated to the stressed syllable. Since it is often very hard to manually locate tonal targets, we privileged an automatic procedure in order to label the Hs and the Ls of our study. For the L points, a particularly hard problem was to locate the $\mathrm{L}$ target within the prenuclear accent. Hence an automatic procedure (see D'Imperio 2000) was employed.

- Finally, we measured the latency between the temporal position of $\mathrm{L}$ and $\mathrm{H}$ pitch targets as defined above.

2.2.4 Acoustic results. This section presents acoustic results for one speaker (SC). The left panel of Figure 3 shows F0 height for the $\mathrm{H}$ target in both prenuclear (first=F) and nuclear (last=L) position. As expected, we found higher $\mathrm{F} 0$ values for the nuclear (last) $\mathrm{H}[\mathrm{SC}: \mathrm{F}(1,29)=6.66$; $p<0.05$; SD: $\mathrm{F}(1,37)=24.8 ; p<0.001]$. Note also a non-significant tendency for prenuclear $\mathrm{Hs}$ to be higher in 3-AP items than in 2-AP items.
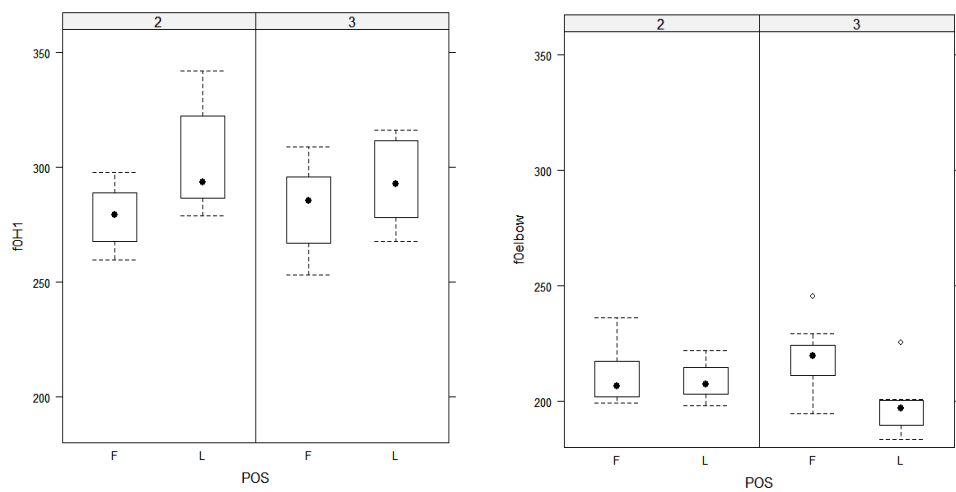

Figure 3: Mean $F 0$ values of the $H$ targets (left) and of the L targets (right) by position within the IP $(F=$ first; $L=$ last $)$ and by number of APs within the IP (2 vs. 3$)$.

F0 values for the $\mathrm{L}$ target are also shown in Figure 3 (right). Position was only significant for speaker $\mathrm{SC}:[\mathrm{F}(1,29)=7.11 ; p<0.05]$. Unexpectedly, we also found a significant interaction between Position and AP-Num, in that $\mathrm{L}$ $\mathrm{F} 0$ values were higher in prenuclear position for 3 -AP items only $[\mathrm{F}(1,29)=$ $4.65 ; p<0.05]$.

Finally, Figure 4 shows alignment results of the $\mathrm{L}$ target relative to stressed syllable onset (left panel), while $\mathrm{H}$ alignment was measured relative to the offset of the stressed vowel (right panel). Note that $\mathrm{L}$ alignment was earlier 
for prenuclear rises $[\mathrm{F}(1,29)=133.24 ; p<0.001]$, while $\mathrm{H}$ alignment was later (closer to stressed vowel offset) for nuclear rises $[\mathrm{F}(1,29)=12.84 ; p<0.005]$, though this measure was less consistent for the prenuclear $\mathrm{H}$.
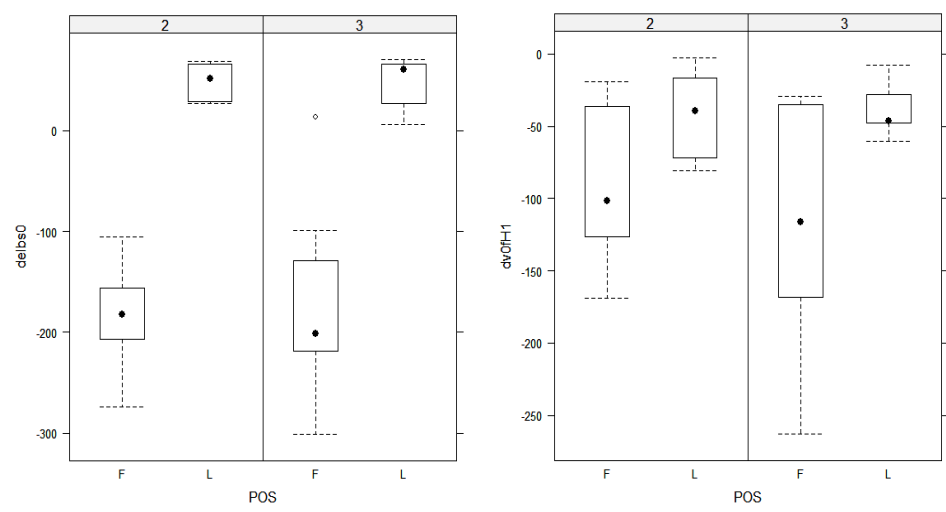

Figure 4: L alignment in ms relative to stressed vowel onset (left) and $H$ alignment relative to stressed vowel offset (right) by position within the IP $(F=$ first; $L=$ last $)$ and by number of APs within the IP (2 vs. 3).
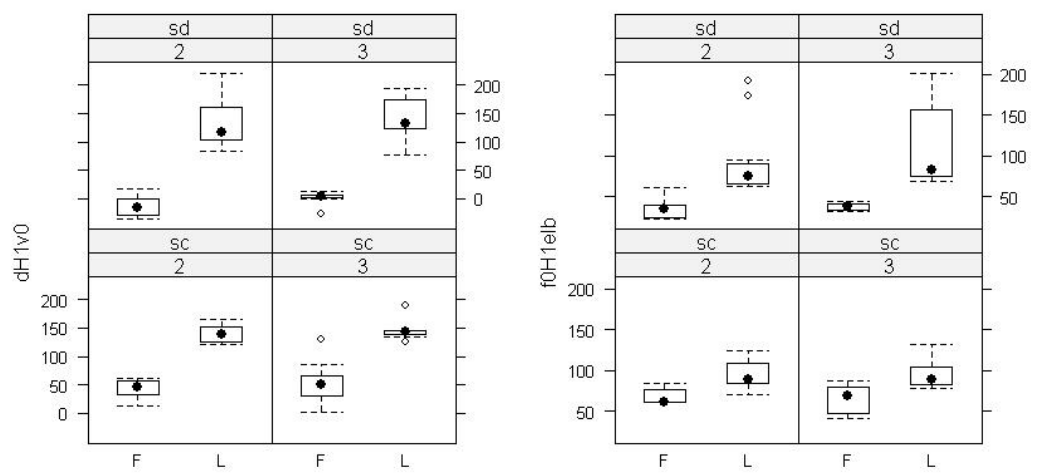

Figure 5: Left panel: $H$ alignment in ms relative to stressed vowel onset for speaker $S D$ (upper) and speaker $S C$ (lower) by position within the IP $(F=$ first; $L=$ last $)$ and by number of APs within the IP (2 vs. 3). Right panel: FO span in $\mathrm{Hz}$ for SD (upper) and SC (lower).

For prenuclear rises it appears that a more consistent alignment measure is the distance between the $\mathrm{H}$ target and the onset of the stressed vowel (v0). Interestingly, though globally both speakers aligned their $\mathrm{H}$ peaks earlier in prenuclear position, the Standard speaker SD aligned it even earlier (Figure 5, left panel), i.e. around the onset of the stressed vowel, with a significant difference between the speakers $[\mathrm{F}(1,67)=19.49 ; p<0.01]$. Moreover, there is 
a tendency for the prenuclear accent span for speaker SD to be smaller than for $\mathrm{SC}$, though this was not statistically significant (Figure 5, right panel).

\section{Discussion}

In this preliminary study, results obtained both from an auditory and a subsequent acoustic investigation of the data do not appear to confirm the hypothesis of a tonal similarity between nuclear and prenuclear accents in French, as predicted by the current autosegmental models of French prosody. On the contrary, they tend to give more credibility to the alternative hypothesis that a formal distinction between these accents must be maintained.

We first verified that the prenuclear (non IP-final) and the nuclear (IP-final) rising accents of left dislocated sentences were indeed perceived as either rises or levels and, second, whether they were immediately followed by an AP or a stronger IP boundary. We thus found that while IP-final accents are always identified as rises, the prenuclear ones are more often transcribed as levels, especially for the Standard French speaker, and that more ambiguity in the transcription is revealed in this position. In fact, the auditory transcription shows a high degree of uncertainty about accent type within the prenuclear position ( $\mathrm{R}$ vs. $\mathrm{S} / \mathrm{H}$ ), while this was not the case for the nuclear position. We interpret this difference as the result of the presence of different pitch accent types marking primary stress according to position within the IP.

The acoustic results were coherent with the auditory transcription in that various melodic and temporal differences were found between the two accent types. First, we found that, as predicted by the presence of a $\mathrm{H} \%$ boundary tone, nuclear rises are higher than prenuclear ones; second that both their $\mathrm{H}$ and $\mathrm{L}$ targets are later than in prenuclear rises.

Note that the alignment differences found cannot be simply accounted for by the presence of a $\mathrm{H} \%$ in nuclear position. In fact, though one could predict a tonal repulsion effect (Silverman and Pierrehumbert 1990) due to the presence of a subsequent $\mathrm{H}$ target (for the boundary tone) after the nuclear accent rise (tonal crowding), the results obtained are unexpected since a later and not an earlier alignment of both $\mathrm{L}$ and $\mathrm{H}$ accentual targets was found in IP-final position. Moreover, the earlier $\mathrm{H}$ alignment in prenuclear position cannot be due to the presence of a L boundary tone or phrase accent marking the end of the AP, since the falling contour which usually follows the AP-final rise does not seem to have a fixed slope (see Jun and Fougeron 2002). An interesting alignment difference was also found for the prenuclear accents of the two speakers, with the Standard French speaker showing an earlier alignment of the $\mathrm{H}$ target as well as a smaller F0 span. This explains the higher score of $\mathrm{S} / \mathrm{H}$ 
(level) transcription scores for this accent type as well as the uncertainty on the part of the transcribers in categorizing it as a proper rise or not.

Therefore, we believe that the old distinction between prenuclear and nuclear accents in traditional intonation studies cannot be completely dismissed for French. These findings are consistent with a very early analysis by Delattre (1966), who proposed to establish a formal distinction between two prosodic levels in French: a "minor continuation" (continuation mineure, i.e. the domain of the prenuclear accent of the present study) and a "major continuation" (continuation majeure, i.e. the domain of the nuclear accent of the present study). The results are also consistent with a recent study related to the dialogical/discursive value of these units within a conversational analysis framework (Portes \& Bertrand 2006).

Hence, we propose that the traditional dichotomy between minor and major continuation (Delattre 1966, Rossi 1999) must be restored in the light of these functional as well as the current formal (phonetic) results. Since there is a strong convergence of results emerging from different material and different experimental conditions, we are naturally inclined to conclude that the distinction between prenuclear and nuclear accentuation can be highly anchored in the cognitive representation of French prosody.

The decision to put forward a formal distinction between a nuclear and a prenuclear accent leads us to raise two complementary questions, which relate respectively to the phonological coding of these prosodic entities and to their relationships with the prosodic domains to which they are associated. Regarding the alignment differences, Di Cristo (in press) hypothesizes that they reflect planification differences that are intended to produce specific perceptual effects, that is a perceived rise in the case of nuclear accents and a high level tone in the case of the prenuclear one. This hypothesis will be tested by mean of perceptual experiments in the future. Another issue has to do with the relationships between the nuclear and prenuclear accents and prosodic phrasing, which appears to be particularly straightforward in French, since these fixed accents are always associated with the final full syllable of a content word. Note that this syncretism has led some authors to deny the existence of an accent in French (Beckman 1992). However, as Dell (1984) has shown, the final strong syllables (which excludes syllables containing a schwa) of French rhythmic groups must be analyzed as being metrically strong. It will be interesting to explore this notion further for Southern varieties, where weak final syllables containing schwa are often produced (e.g. table [ta.bl ] "table"), hence no syncretism between phrase edge and accent position is predicted here. Possible differences in tonal alignment due to this factor will be investigated in future work. 
We have indeed only started to uncover the Standard vs. Southern accent difference in the present work, since we have shown that Standard speakers might mark the prenuclear/nuclear rise difference in a stronger and more consistent way, with the prenuclear accent being most often transcribed as a high level, which can be correlated with some acoustic properties of the same accent. In fact, we found that prenuclear accents for the Standard speaker were aligned much earlier than for the Southern speaker and they also possible showed a smaller F0 span.

Moreover, we found for both speakers a F0 raising effect on the L target of prenuclear rises only in 3-AP, hence longer, items. This result could be due to a global, preplanning effect in line with recent studies on German by Truckenbrodt (2004), since the evidence presented here seem to point to an upstep process within utterances showing more than the 2-APs, and /or by a downstep of the AP-final accent immediately preceding the IP-final AP. The register differences need to be further explored and phonologically motivated.

Finally, the differences reported need further exploration through additional acoustic data coming from different types of corpora, especially spontaneous speech (cf. Portes and Bertrand 2006), in order to isolate the constraints (rhythmic, syntactic, semantic and pragmatic) guiding the construction of domains associated with the nuclear accent. Perception experiments will also be performed in order to verify whether the accent type opposition has a categorical nature and to unravel the layers of intonation meaning associated with each of them.

\section{Conclusion}

In this paper we have shown that the old distinction between prenuclear and nuclear accents in traditional intonation studies cannot be completely dismissed for French, which is supported by both auditory and acoustic differences between IP-final and non-final primary accent shapes. It is quite premature to speculate about the implications of the differences found regarding the number and nature of prosodic constituents in French, since a direct relationship between pitch accent types and phrasing levels could not be established here. The differences reported need further exploration through additional acoustic data as well as perception experiments, to check whether the accent type opposition has a categorical nature.

\section{References}

Arvaniti, Amalia \& Robert D. Ladd. 1995. "Tonal alignment and the representation of accentual targets". In Proceedings of the XIIIth 
International Congress of Phonetic Sciences, ed. by Kjell Elenius \& Peter Branderud, vol. 4, pp. 220-223.

Arvaniti, Amalia, Robert D. Ladd \& Inneke Mennen. 2000. "What is a starred tone? Evidence from Greek". In Papers in Laboratory Phonology V: Acquisition and the Lexicon, ed. by Mike Broe \& Janet Pierrehumbert, pp. 119-131. Cambridge: Cambridge University Press.

Beckman, Mary. 1992. "Evidence for speech rhythm across languages". In Speech Perception, Production and Linguistic Structure ed. By Tohkura, Y., Vatikiotis-Bateson, E. \& Sagisaka, S., 457-463. Tokyo: IOS Press.

Beckman, Mary \& Janet Pierrehumbert. 1986. "Intonational structure in English and Japanese". Phonology 3; 255-309.

Cruttenden, Alan. 1997. Intonation. Cambridge: Cambridge University Press.

Delattre, Pierre. 1966. Studies in French and Comparative Phonetics. Mouton: The Hague.

Dell, François. 1984. "L'accentuation dans les phrases en français". In Forme sonore du langage : Structure des représentations en phonologie, ed. by F. Dell, D.J. Hirst \& J.R. Vergnaud, J.R, 65-122. Paris: Hermann.

Di Cristo, Albert. In press. "Regards sur la prosodie du français." Travaux Interdisciplinaires du Laboratoire Parole et Langage.

Di Cristo, Albert. 1976. "Des indices prosodiques aux traits perceptuels: application d'un modèle d'analyse à l'étude du vocatif en français". Travaux de l'Institut de Phonétique d'Aix, 3. 213-358.

Di Cristo, Albert. 1998. "Intonation in French". Intonation Systems : A Survey of twenty languages, ed. by D.J. Hirst \& A. Di Cristo, 195-218 Cambridge (UK): Cambridge University Press.

Di Cristo, Albert. 1999. "Le cadre accentuel du français contemporain: essai de modélisation". Langues 2(3) : 184-205; 2(4): 258-267.

Di Cristo, Albert \& Daniel J. Hirst. 1993. "Rythme syllabique, rythme mélodique et représentation hiérarchique de la prosodie du français". Travaux de l'Institut de Phonétique d'Aix, 15: 9-24.

D'Imperio, Mariapaola. 2000. The role of perception in defining tonal targets and their alignment, $\mathrm{PhD}$ Thesis, Ohio State University, USA.

D'Imperio, Mariapaola. 2002. "Tonal structure and pitch targets in Italian focus constituents", Catalan Journal of Linguistics 2, pp. 53-63.

D'Imperio, Mariapaola, Robert Espesser, Hélène Loevenbruck, Caroline Menezes, Pauline Welby \& Noël Nguyen. In press. "Are tones aligned with articulatory events? Evidence from Italian and French". Papers on Laboratory Phonology IX, ed. by J. Cole and J. Hualde Oxford : OUP Press. 
Fónagy, Ivan. 1980. 'L'accent en français : accent probabilitaire”. In L'Accent en français contemporain, Studia Phonetica 15, ed. by Fónagy, I. \& Léon, 123-233. P.R. Paris: Didier.

Jun, Sun-Ah. \& Cécile Fougeron. 1995. "The accentual phrase and the prosodic structure of French", In Proceedings of the $13^{\text {th }}$ ICPhS (Stockholm), vol. 2: $722-725$.

Jun, Sun-Ah. \& Cécile Fougeron. 2000. "A phonological model of French intonation". In Intonation: Analysis, Modelling and Technology, ed. by Botinis, A., 209-242. Kluwer Academic Publishers.

Jun, Sun-Ah. \& Cécile Fougeron. 2002. "Realizations of accentual phrase in French intonation", Probus 14: 147-172.

Lacheret-Dujour, Anne \& Frédéric Beaugendre. 1999. La prosodie du français. Paris. CNRS Editions.

Ladd D. Robert, Ineke Mennen \& Astrid Schepman. 2000. "Phonological conditioning of peak alignment of rising pitch accents in Dutch". JASA 107(5): 2685-2696.

Pasdeloup, Valérie. 1990. Modèles de règles rythmiques du français appliqué à la synthèse de la parole. Thèse de doctorat, Université de Provence.

Portes, Cristel \& Roxane Bertrand. 2006. "Some cues about the interactional value of the "continuation" contour in French". Proceedings of IDP05 (Interface-Discourse-Prosody), 8-9 octobre 2005, Aix-en-Provence, France, ed. by Di Cristo A. \& al., CD-ROM.

Post, Brechtje. 2000. Tonal and phrasal structures in French intonation, The Hague : Holland Academic graphics.

Post, Brechtje, Elisabeth Delais-Roussarie \& Anne-Catherine Simon. 2006. "IVTS, un système de transcription pour la variation prosodique". Prosodie du français contemporain, l'autre versant de PFC, Bulletin PFC ed. by Simon, A.C., Caelen-Haumont, G. and C. Pagliano, vol.6: 51-68.

Prieto, Pilar, Jan P. H. van Santen \& Julia Hirschberg. 1995. "Tonal alignment patterns in Spanish". Journal of Phonetics, 23: 429-451.

Prieto Pilar, Mariapaola D'Imperio \& Barbara Gili Fivela. 2005. "Pitch accent alignment in Romance : primary and secondary associations with metrical structure". Language and Speech, special volume on Intonation in Language Varieties, ed. by P. Warren, 48(4): 359-396.

Rossi, Mario. 1999. L'intonation du français : description et modélisation. Paris, Ophrys.

Selkirk, Elisabeth O. 1972. The Phrase Phonology of English and French. Doctoral Dissertation. MIT.

Selkirk, Elisabeth O. 1984. Phonology and Syntax:The Relation between Sound and Structure. Cambridge (MA): MIT Press. 
Silverman Kim \& Janet Pierrehumbert. 1990. "The timing of prenuclear high accents in English". In Papers in Laboratory Phonology I: Between the Grammar and Physics of Speech ed. by John Kingston \& Mary Beckman: 71-106. Cambridge: Cambridge University Press.

Truckenbrodt, Hubert. 2004. "Final lowering in non-final position". Journal of Phonetics 32: 313-348.

Vaissière, Jacqueline. 1974. “On French Prosody”. Quarterly Progress Report (MIT), 114: 212-223.

Welby, Pauline. 2006. "French intonational structure: Evidence from tonal alignment". Journal of Phonetics, 34(3): 343-371.

Welby, Pauline \& Hélène Lœvenbruck (in press). "Anchored down in Anchorage: Syllable structure and segmental anchoring in French". Italian Journal of Linguistics, ed. by M. D'Imperio, vol. 18. Special issue on "Autosegmental-metrical approaches to intonation in Europe: tonal targets and anchors". 